\title{
Review of: "Asymmetric response of interfacial water to applied electric fields"
}

\author{
Changqing Sun ${ }^{1}$ \\ 1 Nanyang Technological University
}

Potential competing interests: The author(s) declared that no potential competing interests exist.no potential competing interests

VSFG investigation [1] revealed the asymmetrical response of the surface heavy water $\left(D_{2} O\right)$ dipoles to the charge polarity of the graphene electrode, evidencing the nonlinearity of the surface water dielectrics. A peak of non-hydrogen-bonded OD groups at a frequency of $2,700 \mathrm{~cm}^{-1}$ is presented. The OD points away of water surface at a $5 \times 10^{12}$ electrons $/ \mathrm{cm}^{2}$ negative electrode charge density. However, at neutral or positive electrode potentials, this 'free-OD' peak disappears abruptly, and the spectra display broad peaks of hydrogen-bonded OD species $\left(2,300-2,650 \mathrm{~cm}^{-1}\right)$. This observation demonstrates the nonlinear dielectric response of the surface water to electric fields of about $\pm 3 \times 10^{8} \mathrm{~V} / \mathrm{m}$. Furthermore, the G-mode frequency of the graphene electrode undergoes a blueshift by some $10 \mathrm{~cm}^{-1}$ under electrification. The findings contributed to knowledge of the interfacial water dielectrics at the atomic scale and discovered the graphene G-mode response to electrification.

This reader would like to share his experience, as supplementary information, in exploring the effect of atomic undercoordination and directional electrostatic polarization on the phononic performance of the skin water [2-4] and graphene [5]:

1. The phonon frequency shift that is proportional to $\left(E / d^{2}\right)^{1 / 2}$ reflects the perturbation to the oscillator energy $\mathrm{E}$ and length $\mathrm{d}$. The blue shift indicates the stiffening of the the electrode $\mathrm{C}-\mathrm{C}$ bond and stiffness distribution of the $\mathrm{D}-\mathrm{O}$ bonds in different coordination environment.

2. Molecular undercoordination shortens and stiffens the intramolecular $\mathrm{H}(\mathrm{D})-\mathrm{O}$ bond, and meanwhile, lengthens and softens the O:H(D) nonbond associated with strong polarization of the lone pair electrons (https://www.qeios.com/read/FO6KAP). Being gel-like, viscoelastic, less dense, hydrophobic, frictionless (for ice), mechanically and thermally stable, the supersolid skins of water and ice share the identical $\mathrm{H}-$ $\mathrm{O}$ bond of $3450 \mathrm{~cm}^{-1}$ vibration frequency. Thus, vibration frequency of the free $\mathrm{H}(\mathrm{D})-\mathrm{O}$ radical is higher than that of water skin and even higher than it is in the bulk.

3. Directional field electrification enhances the effect of molecular under-coordination on the skin supersolidity. DFT calculations [6] confirmed that $\mathrm{H}_{2} \mathrm{O}$ molecules of the $\left(\mathrm{H}_{2} \mathrm{O}\right)_{6-20}$ clusters remain their tetrahedral structures with titled orientation under polarization. The electrification stretches the O:H from 1.86 till break at $1.91 \AA$, for instance. The breaking limit varies with cluster size. If the field 
intensity is sufficiently strong, molecular dipoles will reorient oppositely along the field direction; at the critical intensity, the $\mathrm{O}: \mathrm{H}(\mathrm{D})$ will break, easing evaporation but hindering $\mathrm{H}(\mathrm{D})-\mathrm{O}$ dissociation, as electrification shortens and stiffens the $\mathrm{H}-\mathrm{O}[4]$.

4. Water electrification exhibits many anomalies such as Armstrong's water floating bridge [7], Dufour's electrofreezing [8], and Asakawa's electro-evaporation [9].

5. How the electrification stiffens the $\mathrm{C}-\mathrm{C}$ bond of the electrode remains an open question. That electrification shortens the intramolecular $\mathrm{C}-\mathrm{C}$ bond is very challenging, which appears to happen to the strongly coupled systems - the nonbonding pai-electron may play a certain yet unclear role.
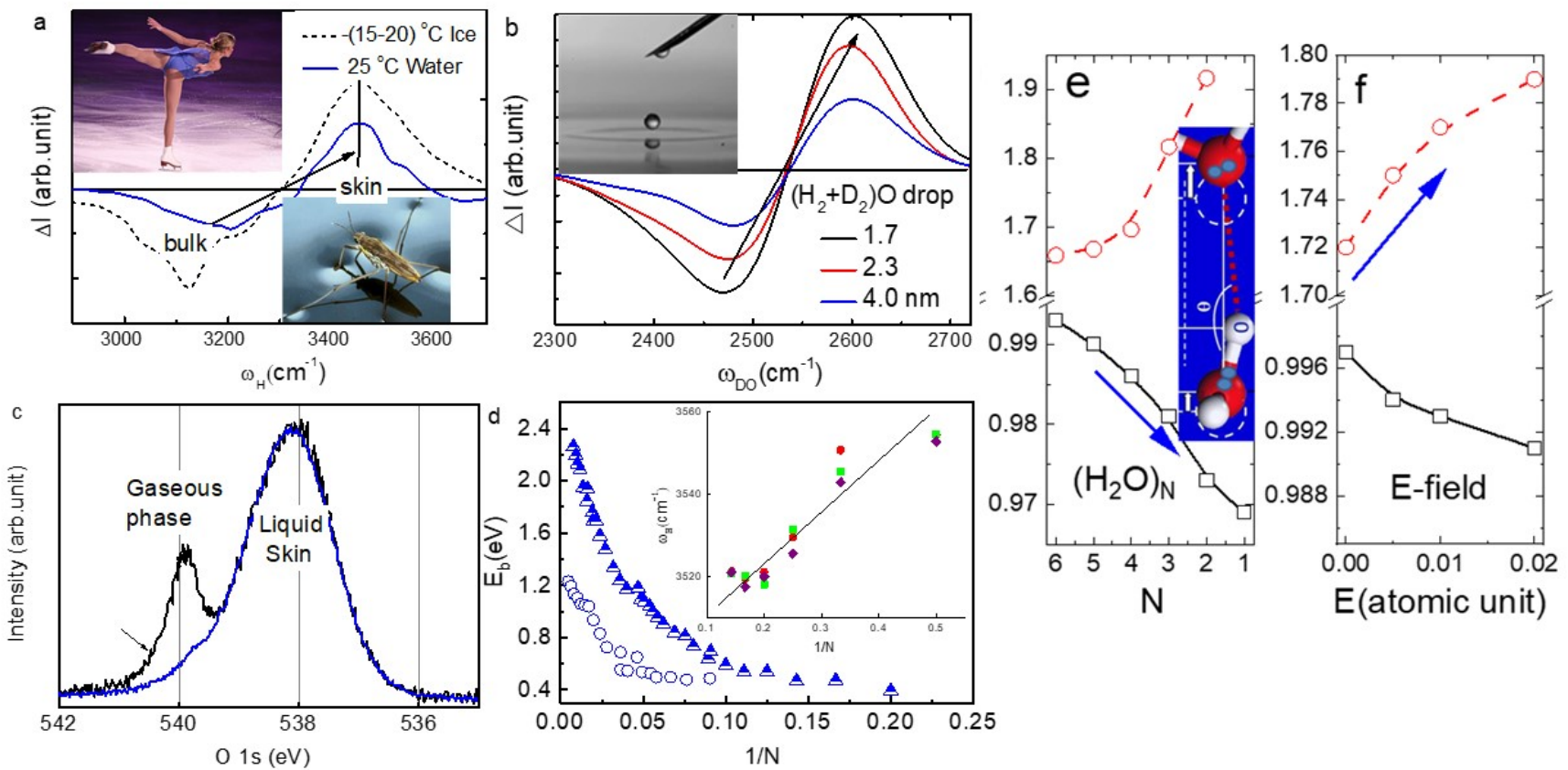

Fig. $1 \mathrm{H}-\mathrm{O}$ bond stiffness transition from the bulk reference to the supersolid skins of (a) $298 \mathrm{~K}$ water, $258 \mathrm{~K}$ ice [10], and (b) $(0.05 \mathrm{D}+0.95 \mathrm{H})_{2} \mathrm{O}$ nanodroplets [11]. The $\mathrm{H}-\mathrm{O}$ contraction entraps (c) O1s electrons from the bulk (536 Ev) to the skin (538) and the gaseous water $(530 \mathrm{eV}$ ) [12]. The densely entrapped core electrons polarize in turn (d) the nonbonding electrons from the bulk core $(3.2 \mathrm{eV})$ to the interior $(2.4 \mathrm{eV})$ and the skin $(1.2 \mathrm{eV})$ for the sized droplets $(\mathrm{N})$. Droplet size reduction enhances the polarization till $0.4 \mathrm{eV}$ for $\mathrm{N}=5$ [13]. Inset d shows the cluster size reduction induced $\mathrm{H}-\mathrm{O}$ frequency blueshift. (e) Cluster $\left(\mathrm{H}_{2} \mathrm{O}\right)_{\mathrm{N}}$ size reduction and (f) electrostatic polarization do shorten the $\mathrm{H}-\mathrm{-O}$ bond and lengthens the O:H, according to the Forcefield calculations [14].

I hope this supplementary could help in understanding the performance of the interfacial water under electrification from the perspective of hydrogen bonding cooperativity (Fig 1 inset e). Critiques and comments are welcome and appreciated.

1. Montenegro, A., et al., Asymmetric response of interfacial water to applied electric fields. Nature, 2021. 594(7861): p. 62-65.

2. Zhang, X., et al., A common supersolid skin covering both water and ice. Physical Chemistry 
Chemical Physics, 2014. 16(42): p. 22987-22994.

3. Sun, C.Q., Rules essential for water molecular undercoordination. Chinese Physics B, 2020. 8(8): p. 088203.

4. Sun, C.Q., Water electrification: Principles and applications. Advances in Colloid and Interface Science, 2020. 282: p. 102188.

5. Yang, X., et al., Multifield-resolved phonon spectrometrics: structured crystals and liquids. Progress in Solid State Chemistry, 2019. 55: p. 20-66.

6. Rai, D., et al., Exploring electric field induced structural evolution of water clusters, $(\mathrm{H} 2 \mathrm{O}) \mathrm{n}[\mathrm{n}=9$ 20]: density functional approach. J Chem Phys, 2013. 138(4): p. 044304.

7. Armstrong, W., Electrical phenomena The Newcastle Literary and Philosophical Society. The Electrical Engineer, 1893. 10: p. 153.

8. Dufour, L., Uber das gefrieren des wassers und uber die bildung des hagels. Poggendorfs Ann. Physik, 1861. 114: p. 530-554.

9. Toda, S. and Y. Asakawa, Studies on the improvement of fuel combustion and vapour evaporation of small steam boiler: Effect of high voltage. Bulletin of the College of Agriculture and Veterinary Medicine Nihon University, 1976.

10. Kahan, T.F., J.P. Reid, and D.J. Donaldson, Spectroscopic probes of the quasi-liquid layer on ice. Journal of Physical Chemistry A, 2007. 111(43): p. 11006-11012.

11. Park, S. and M.D. Fayer, Hydrogen bond dynamics in aqueous $\mathrm{NaBr}$ solutions. Proceedings of the National Academy of Sciences of the United States of America, 2007. 104(43): p. 16731-8.

12. Winter, B., et al., Hydrogen bonds in liquid water studied by photoelectron spectroscopy. Journal of Chemical Physics, 2007. 126(12): p. 124504.

13. Verlet, J.R.R., et al., Observation of large water-cluster anions with surface-bound excess electrons. Science, 2005. 307(5706): p. 93-96.

14. Huang, Y.L., et al., Hydrogen-bond relaxation dynamics: Resolving mysteries of water ice. Coord Chem Rev, 2015. 285: p. 109-165. 